\title{
Imagem da cidade: a experiência por diferentes modais
}

\author{
City image: the experience through diferente modals
}

\author{
GANSKE, Morgana Creuz; Mestra em Design; UNIVILLE - Universidade da Região de Joinville \\ morganacreuz.mc@gmail.com \\ EVERLING, Marli Teresinha; Doutora em Design e Sociedade; PUC-Rio \\ marli.everling@gmail.com
}

\section{Resumo}

Este artigo é um recorte dos estudos realizados no projeto de pesquisa ETHOS ${ }^{1}$ que visavam a análise do design gráfico como facilitador da cultura de cuidado com a cidade. Seu objetivo é considerar a experiência de moradores de Joinville/SC (entre 20 e 40 anos) em diferentes modais, identificando fisionomia, personalidade e comportamento da cidade. Para tal, empregou-se a pesquisa bibliográfica e entrevista estruturada, com base no modelo proposto por Lynch (2011). Os resultados obtidos reforçam a importância dos conceitos defendidos por alguns urbanistas, como Gehl (2013), que sustentam a inserção da dimensão humana no planejamento urbanístico das cidades, além de ressaltar a importância do investimento na forma visual e no viver a cidade.

Palavras Chave: experiência; design; imagem e cidade.

\begin{abstract}
This article is an excerpt from research developed at ETHOS ${ }^{2}$ Project which aimed at the analysis of graphic design as a facilitator of the culture of care with the city. The objective is to consider the experience of Joinville residents (between 20 and 40 years old) in different transportation modal to identify physiognomy, personality and behaviour of the city. For this, bibliographical research and structured interviews were used, based on the model proposed by Lynch (2011). The results obtained reinforce the importance of the concepts defended by some urbanists, such as Gehl (2013), who support the insertion of the human dimension in the urban planning of cities, besides emphasizing the importance of investing in visual form and living the city.
\end{abstract}

Keywords: experience; design; image and city.

\section{Introdução}

A imagem está presente no cotidiano da sociedade de inúmeras formas, sendo concretizada por motivações distintas. Associada à representação e eternização de um fato, este tipo de linguagem se perpetua há séculos. Como consequência, observa-se uma evolução significativa nos

\footnotetext{
${ }^{1} \mathrm{O}$ projeto ETHOS tem como foco o desenvolvimento de atividades relacionadas com o design, no que tange a cultura da participação, o novo design, o protagonismo, a sustentabilidade e as relações de uso.

${ }^{2}$ The ETHOS project focuses on the development of activities related to design, which is not a culture of participation, new design, leadership, sustainability and usage relations.
} 
formatos de materialização destas. Pinturas primitivas foram, em parte, substituídas pela máquina como ferramenta de captura, entretanto observa-se um movimento de que se apropria das primeiras formas de representação para resgate histórico e cultural. O fato é que a sociedade como um todo, tem a necessidade de eternizar os fatos, por meio da representação imagética.

A característica mais marcante das imagens é a sua tangibilidade, entretanto o domínio imaterial, ou seja, as construções mentais projetadas e as percepções de cada cidadão, também se configuram como classificação imagética (SANTAELLA e NORTH, 2008). Neste contexto, cita-se os modelos mentais projetados pelos indivíduos. De acordo com Lynch (2011) as pessoas constroem inconscientemente modelos mentais dos locais que conhecem, de acordo com o seu repertório. Tal característica explica as diferentes percepções, descrições e experiências com um mesmo local. Plano de fundo (e superfície) de muitas histórias e de representações imagéticas, as cidades se configuram como lugares para vivência e troca de experiências. As percepções variam de acordo com os elementos visuais, sobre os quais a cidade se configura (LYNCH, 2011). Ruas, rótulas, prédios históricos, sinais de trânsito auxiliam na construção do pensamento, no rastreamento mental de referências e na projeção da imagem de um local.

Com base nesse contexto o objeto deste estudo visa (por meio de ferramentas de pesquisa e análise do design) explorar a fisionomia, personalidade e comportamento de uma região da cidade de Joinville/SC, identificando a imagem que moradores de 20 a 40 anos, homens e mulheres, que utilizam diferentes tipos de locomoção pela cidade, com objetivos diversos (dirigir-se ao trabalho, estudo, resolução de questões diárias ou para lazer) possuem da cidade. Tal universo de pesquisa foi escolhido, em virtude de diferentes objetivos e estilo de vida deste público, bem como, a transição presente nesta fase da vida. O método de pesquisa definido é baseado na observação direta intensiva e na entrevista estruturada com base na metodologia de Lynch (2011). Os resultados refletem a interferência dos meios de locomoção para com a construção do modelo mental da cidade, bem como o repertório de cada indivíduo influencia na construção da imagem ambiental.

O presente artigo está estruturado em duas partes; na primeira apresenta-se um aprofundamento teórico sobre a imagem, a cidade, os elementos visuais que à compõem e o design urbano. Já na segunda parte apresentam-se os resultados da análise dos insights da entrevista. Inicia-se o estudo buscando a compreensão da linguagem imagética, utilizando como bases teóricas autores como: Debray (1992) que defende que a arte nasce da morte; Plaza (1986) e Flusser (2002) que apresentam o sentido da imagem como representação e perpetuação; Santaella e North (2008) que discutem os dois domínios da imagem: imaterial e material; e, Mithell (apud CONTRERA e HATTORI, 2003) que classifica as imagens de forma mais abrangente em cinco categorias: gráficas, ópticas, perceptuais, mentais e verbais.

\section{Conceitos de imagem}

A utilização das imagens como linguagem é datada dos primórdios da humanidade, sendo estas consideradas "a infância do signo" (DEBRAY, 1992, p.60). Por meio delas, o homem iniciou o processo de eternizar o que pensava, sentia e como vivia. Alguns autores defendem que as imagens podem interferir na história das sociedades (ROMÃO, 2010; ALBERNAZ, 2009).

O conceito de imagem é variável, de acordo com o foco de estudo. Em uma reflexão conotativa, Contrera e Hattori (2003, p. 26), definem imagem como "um termo que comumente 
utilizamos para designar representações gráficas ou verbais de algo que existe ou poderia existir". Zunzunegui (apud GASTAL, 2005, p.48) afirma que a "imagem é um suposto de comunicação visual, no qual se materializa um fragmento do universo perceptivo e que apresenta a característica de prolongar a sua existência ao longo do tempo". Já Joly (1996) alerta que uma imagem só se assemelha a outro item. Tal condição posiciona as imagens como representação, ou seja, "ela se parece com a coisa, porém não à é, sendo definida, portanto, como signo analógico, que tem na semelhança o seu princípio de funcionamento (SILVEIRA, 2005, p.115)".

Plaza (1986, p. 08) afirma que "a imagem nascia nas mentes antigas e pré-históricas como modelo cosmogônico, para similaridade que parava o tempo". A imagem "surge como uma espécie de blindagem da carne corruptível, uma vez que, para os antigos, ela não é pura representação, uma metáfora, mas um verdadeiro prolongamento físico" (ROMÃO, 2010, p.84). Nesse contexto, o autor baseado na teoria de Debray (1992) reflete sobre a realidade representada de forma imagética nas cavernas, a fim de perpetuá-la para toda a eternidade: "A arte da representação, da imagem sempre teve a função de estabilizar o instável, de imortalizar o mortal, de mostrar o infinito à nossa finitude" (ROMÃO, 2010, p.85). É perceptível na contemporaneidade que este ideal ainda se faz presente. É fato que a forma de representação foi alterada. Os desenhos nas cavernas foram substituídos por fotografias, filmagens, grafites, ilustrações, mas as imagens continuam perpetuando os momentos e contando histórias. As cidades são plano de fundo de inúmeras histórias de seus moradores e, verifica-se que simultaneamente, o cotidiano destas é representado junto a dos seus cidadãos.

A representação por meio das imagens, é alicerçada nos valores culturais da sociedade que as desenvolve. Ressalta-se que tais elementos permitem a interpretação completa por parte dos indivíduos que compreendem tais códigos, enquanto para os não detentores a significação é superficial. Albernaz (2009, p.26) destaca que "a imagem é subjetiva, pois perpassa a compreensão de quem a representou e de quem a percebe". Entretanto, ressalta-se a universalidade da imagem, ao compará-la com a linguagem verbal. Silveira (2005) afirma que alguns teóricos, defendem a linguagem por meio da imagem como universal, visto que uma rápida leitura de um texto composto por imagens, pode ser compreendido por pessoas que falam as mais diferentes línguas. Outro aspecto positivo da imagem apontado pela autora, é a possibilidade de leitura em menos tempo, além do fato que este tipo de linguagem desperta o prazer estético, conforme destacado por Joly (1996). Observa-se que as imagens auxiliam na construção do pensamento e estímulo as ideias. Fato este comumente observado nos livros infantis, que contam as histórias por meio das imagens, auxiliando na formação cognitiva e do intelecto das crianças. A universalidade das imagens, ou seja, a facilidade de compreendê-las em diferentes culturas e a harmonia visual que elas refletem, é representada nos dias de hoje por meio de diversas formas de representação, dentre as quais destaca-se os pictogramas. Muito utilizados na sinalização de locais públicos e privados, estes auxiliam na construção do pensamento lógico dos cidadãos nas cidades. Diferente da linguagem verbal, eles são compreendidos pela maioria, que mesmo sem contato anterior com a imagem facilmente identifica a mensagem representada.

Flusser (2002, p.09) discorre acerca da representação, afirmando que "as imagens são mediações entre homem e mundo. O homem 'existe', isto é, o mundo não lhe é acessível imediatamente. Imagens têm o propósito de representar o mundo". Neste contexto, observa-se a importância das imagens no processo de representação, construção do pensamento e eternização de um momento. Os diferentes tipos de imagem têm como objetivo a perpetuação de um instante. Muito do que a sociedade contemporânea compreende sobre os períodos passados é decorrente 
das representações imagéticas perpetuadas. Compreende-se, assim, sua importância nas diferentes esferas do mundo. Analisando o cenário atual, observa-se que as representações visuais que possuem a cidade como superfície, são diferenciadas e orgânicas acompanhando a sua superfície. Nota-se que o objetivo e motivação da expressão, também foram modificados, especialmente, por meio de grafites, intervenções urbanas, que reconfiguram formatos de expressão. Segundo Melendi (apud MAZETTI, 2006, web) nos dias atuais "as intervenções são uma reação contra a degradação do espaço público".

As imagens possuem perspectivas diversas, conforme pode ser observado na teoria de Santaella e North (2008). As autoras consideram dois domínios, sendo o primeiro das representações visuais e o segundo do domínio imaterial. Silva $(2014$, p.15) afirma que "as representações visuais abrangem os desenhos, pinturas, gravuras, fotografia, cinema, televisão, vídeo, holografia e infográficas, todas tangíveis. Já o segundo domínio, o imaterial, representa a mente, as visões, a imaginação, esquemas e modelos mentais". A autora destaca que a tangibilidade das representações imagéticas é um fator variável diversificado por meio de processos individuais. Percebe-se que os dois domínios transitam por uma linha tênue, visto que "não existe separação entre ambos, pois para a materialização do primeiro é necessária a estruturação expressiva em seus devidos suportes" (IBID, p.15). Percebe-se a relevância da imagem como forma de expressão do pensamento, o que traz ainda mais ênfase à visão. Sabe-se que é por meio dela que o ser humano realiza seu primeiro contato sensorial com o mundo. Neste contexto, a autora aborda o fato de que as "imagens visualizadas no cotidiano são primeiramente projeções formadas no interior do cérebro, a partir do processo do aparelho ocular. No entanto, a compreensão e assimilação dessas imagens dependem das relações sociais e culturais que o indivíduo tem com o mundo" (IBID, p,15). Para análise do objeto de estudo deste artigo, será utilizado como base o domínio imaterial, pois serão analisadas as percepções dos cidadãos, a respeito da imagem que eles fazem da cidade de Joinville. Para tal, serão utilizadas características do primeiro domínio, das representações visuais. Tal fenômeno considera a teoria de Santaella e North (2008) quanto a impossibilidade de separação dos domínios, visto que é por meio de um, que o outro se materializa.

A classificação das imagens é estudada por diferentes teóricos, sendo que cada qual as categoriza a seu modo. Observa-se, em sua maioria, que tais classificações derivam de uma mesma essência, entretanto, cada autor utiliza conceitos distintos. Mithell (apud CONTRERA e HATTORI, 2003) categoriza a imagem em cinco domínios: gráficas, ópticas, perceptuais, mentais e verbais. Esta classificação se assemelha com os estudos de Santaella e North (2008) entretanto, o autor fraciona os dois domínios apresentados anteriormente. Analisando as cinco categorias de imagem (gráficas, ópticas, perceptuais, mentais, verbais) Silveira (2005) exemplifica as imagens gráficas, como pinturas, estátuas e desenhos; as ópticas, como espelhamento e projeção; as perceptuais associadas aos sentidos e aparência; as mentais, construídas nos sonhos, nas ideias e na memória; e as verbais, descritas por palavras e metáforas. Tais classificações, permitem o entendimento da influência das imagens na sociedade, além de auxiliar na compreensão da sua percepção. Neste estudo sobre a imagem acerca da imagem da cidade que os moradores de Joinville possuem, serão explorados três domínios da imagem apresentados pelo autor: as imagens gráficas usadas para representar cidade, as perceptuais, para análise dos sentidos despertados durante os trajetos dos entrevistados, e, as imagens verbais, associadas à palavras, por meio de metáforas que auxiliam na construção do imaginário representativo das cidades. Conforme observado, as imagens possuem diferentes contextos e classificações. De acordo com o foco de estudo elas representam, orientam, 
narram e significam. Com base no objeto deste artigo, na sequência serão analisados os conceitos imagéticos com foco na cidade.

\section{A imagem da cidade}

Percebe-se que a cidade configura o plano de fundo da maioria das representações idealizadas pela sociedade. Independente da característica, domínio ou motivação, as imagens buscam a perpetuação de um instante, a projeção de um modelo mental, uma lembrança. Com a evolução da sociedade, os meios de utilização imagética foram reconfigurados, e em paralelo aos meios, os influenciadores do espaço para representação de algo também evoluíram. As cidades são lugares de encontro, de passagem, de intervenções, de negócios, de passeio... enfim, são o cenário da vida dos cidadãos. Observa-se que há ciclos de valorização destes espaços, uma vez que estes eram tidos como coadjuvantes da história de seus moradores. Entretanto, conforme afirma Lefebvre (2006, p.04) "as cidades são centros de vida social e política onde se acumulam não apenas as riquezas, como também os conhecimentos, as técnicas e as obras".

A imagem e o design de uma cidade conforme Lynch (2011, p.01) é uma arte temporal, visto que "a cada instante, há mais do que o olho pode ver, mais do que o ouvido pode perceber, um cenário ou uma paisagem esperando para serem explorados". O autor reflete sobre a percepção (fragmentada) da cidade, e afirma que a combinação de todos os sentidos auxilia na concepção de um modelo mental mais realístico do local. Em seu estudo sobre a imagem da cidade, Lynch (2011) elenca conceitos fundamentais para a representação imagética da cidade por seus moradores, a legibilidade, a imaginabilidade, a identidade, estrutura e significado. O primeiro conceito abordado é o da legibilidade, sendo definido pelo autor como a formulação de um padrão coerente, em que as partes são organizadas, planejadas e alinhadas de tal modo a corroborar com a facilidade de entendimento. Um ambiente legível transmite segurança e bem-estar aos seus moradores e turistas. Tal característica possibilita elevada experimentação urbana, visto que, em sua dimensão visual, expressa toda a sua complexidade. É fato que o sentir-se perdido em um ambiente, provoca sensações negativas, deformando a imagem da cidade; ao conseguir se localizar, de acordo com o autor, o indivíduo sentese seguro, equilibrado e aberto às experimentações que o ambiente tem a oferecer. Tal sensação, aflora o sentimento da terra natal, oportunizando a segurança emocional. A imaginabilidade, outro conceito fundamental abordado pelo autor, é definida como a "qualidade de um objeto físico que lhe dá uma alta probabilidade de evocar uma imagem forte em qualquer observador. Refere-se à forma, cor ou arranjo que facilitam a formação de imagens mentais do ambiente fortemente identificadas, poderosamente estruturadas e altamente úteis" (IBID, p.11). Observa-se que ambos os conceitos se complementam, a fim de construir imagens fortes e representativas das cidades.

Conforme Lynch (2011) a imagem ambiental é definida por meio de três componentes atados: identidade, estrutura e significado. O primeiro aspecto é relacionado a unicidade de um ambiente urbano, ou seja, cada cidade possui suas características e particularidades, definidas em parte pela identidade de seus cidadãos. O segundo componente, a estrutura, é definido como a relação do objeto com o observador e com os outros objetos. O terceiro aspecto, aborda a concepção de um significado seja ele prático ou emocional. Verifica-se que os conceitos fundamentais elencados por Lynch (2011) se aproximam da teoria de Santaella e North (2008), na medida em que enfatizam o arranjo visual de domínio material auxiliando a construção do sentido 
imaterial e vice-versa. Logo um observador pode ainda construir um modelo mental de um espaço e por meio das representações visuais concretizá-lo.

Anholt (2010) destaca que a imagem de um território deve ser conquistada. Kotler (2000) ressalta que a imagem de um local é a soma de crenças, ideias e impressões que um indivíduo tem sobre este. Logo, a imagem percebida varia de acordo com o que veem e sentem do espaço. Silva $(2014$, p.12) define que os sentimentos despertados por uma cidade, estão associadas às vivências, "e/ou à maneira pela qual o indivíduo integra-se aos aspectos sociais, econômicos, culturais e simbólicos, às lembranças que a cidade produz no imaginário, possibilitando a sua existência virtual, que extrapola o tempo e o espaço". Neste contexto, é válido distinguir os termos imagem e identidade da cidade. Imagem, é como o cidadão percebe e sente o espaço, ou seja, a tradução das ações realizadas, a fim de criar um modelo mental favorável do ambiente. Já identidade, são os valores e experiências reais de um local que auxiliam na materialização de um espaço, ou seja, as ferramentas utilizadas para que a imagem seja percebida (KOTLER, 2000). Na sequência serão abordados os elementos visuais que contribuem para com a construção dos conceitos apresentados: legibilidade, imaginabilidade e identidade, estrutura e significado. Tais elementos auxiliam na construção e identificação da imagem da cidade.

\section{Os elementos visuais da cidade}

Compreender a ambiência urbana, a fim de projetar espaços que ofereçam benefícios para a população tem sido a priori atribuição do governo de muitas cidades. Entretanto, os modelos de planejamento estão ultrapassados, visto que compreendem a construção da imagem da cidade do ponto de vista estético e funcional, não considerando aspectos sociais e humanos. Conforme abordado por Gehl (2013) e Jacobs (2011) há algum tempo a dimensão humana tem sido negligenciada como fator chave para tomada de decisões, no que tange o planejamento urbano. Tal "esquecimento", culmina na imagem de uma cidade cinza, repleta de fumaça, trânsito, que é regida pelo som das buzinas e das máquinas, não permitindo a vivência nos espaços públicos. Uma cidade é construída por seus moradores. Ruas, bairros, monumentos históricos, praças, e outros espaços estão carregadas de significados e lembranças das pessoas que ali foram criadas, ou que por algum motivo, tiveram suas vidas marcadas por aquele ambiente. Lynch $(2011$, p.01) destaca que "cada cidadão tem vastas associações com alguma parte de sua cidade, e a imagem de cada um está impregnada de lembranças e significados". Malheiros $(2015$, p.74) converge com esta abordagem ao relatar que "a imagem contemporânea da cidade é resultante da acumulação de épocas. É repleta de signos informantes do passado, dispersos no ambiente urbano - objetos de civilização [...] que atuam como produto da ação cultural humana".

De acordo com Lynch (2011) a construção da imagem da cidade é realizada de acordo com o que cada cidadão visualiza, organiza e interpreta. Cardoso, Scherer e Zavadil (2011, web) sustentam a proposição de que o autor, introduziu o termo wayfinding (orientação espacial) em 1960, estabelecendo que cada indivíduo preconiza elementos visuais para se localizar no espaço: ruas, mapas, números de casas, estabelecimentos comerciais, cruzamentos, entre outros. Elencando tais elementos cada indivíduo organiza-os em mapas cognitivos, que o autor define como imagem mental da cidade. Estes mapas são acrescidos de informações pessoais das referências que cada indivíduo carrega consigo e de suas vivências e experiências com determinado ambiente. Este método resulta na criação de imagens individuais, logo a divergência entre as imagens da cidade é uma constante. Nesse contexto continua 
verdadeira a consideração de Aristóteles (apud SENNETT 2003, p.13) "uma cidade é construída por diferentes tipos de homens; pessoas iguais não podem fazê-la existir". Destaca-se que as vivências individuais contribuem para essa organização imagética mental da cidade; pessoas que transitam pelo espaço público a pé, de bicicleta, de carro ou de transporte público constroem imagens diferenciadas em virtude das restrições e possibilidades vinculadas a sua trajetória na cidade

Visando abordar apenas os elementos físicos, deixando em segundo plano os aspectos sociais, emocionais e históricos de construção da imagem, Lynch (2011) elencou cinco elementos físicos básicos, que estruturam a idealização da imagem da cidade, são eles: as vias, os limites, os bairros, os pontos nodais e os marcos. $\mathrm{O}$ autor define como primeiro elemento físico as vias, que são "os canais de circulação ao longo dos quais o observador se locomove de modo habitual, ocasional ou potencial. Podem ser ruas, alamedas, linhas de trânsito, canais ferrovias" (LYNCH, 2011, p.52). O autor afirma que é por meio deste elemento, que grande parte da sociedade constrói sua imagem da cidade, visto que utilizam destas referências para criar seus mapas mentais. 0 segundo elemento físico apresentado são os limites, ou seja, as fronteiras, quebras de continuidade como as praias e margens de rios, as construções, os trilhos das ferrovias, tapumes de construção. Estes também auxiliam na construção das imagens mentais, entretanto não são tão dominantes como os sistemas viários. Os bairros, são o terceiro elemento físico elencado por Lynch, sendo definidos como as regiões que compõem as cidades, sejam elas médias ou grandes. Muitos cidadãos estruturam a cidade, por meio das referências dos bairros, que são considerados individuais em sua essência. O quarto elemento são os pontos nodais definidos como lugares estratégicos de uma cidade, por meio dos quais o observador decide como se locomover. Citam-se as rótulas, os cruzamentos, convergências de vias, entre outros. Este elemento também é conhecido como núcleo, visto que é um centro para o qual os indivíduos devem tomar uma decisão para continuação da sua locomoção. Finalizando, o quinto elemento são os marcos, em que o observador os analisa externamente. Os marcos são vistos, analisados e inseridos mentalmente de diversos ângulos e distâncias, visto que são: os edifícios, semáforos, lojas, fachadas, grandes montanhas, o próprio Sol, entre outros. Diversos são os marcos que podem ser inseridos para facilitar a imagem de um determinado ambiente, cabe ao indivíduo identificar quais possuem mais representatividade para sua construção mental da cidade. Lynch (2011) afirma que estes elementos (matéria-prima para construção da imagem das cidades) devem ser analisados coletivamente, a fim de se estabelecer uma resposta satisfatória sobre a imagem do ambiente. Quando relacionados, os cinco elementos compõem detalhamentos para o mapeamento do ambiente. Neste contexto, o autor afirma que as imagens são processadas em níveis, em que com a variação da escala da área e em aspectos como a hora do dia e a estação do ano, o observador passa "de uma imagem da rua a uma do bairro, da cidade ou da região metropolitana" (IBID, p.95).

Em virtude da relevância de identificar os aspectos de design associados a cidade e compreender a relação entre estes e a construção da imagem do ambiente urbano pelos indivíduos, a seguir serão abordados conceitos que auxiliam na verificação da forma com a qual o design colabora, instiga ou deturpa a construção deste modelo mental.

\section{O design associado à cidade}

A temática cidade é há muito tempo o plano de estudo de áreas como arquitetura, urbanismo e planejamento urbano. Entretanto, observa-se que os projetos de melhoria dos espaços 
públicos, possibilitando a experimentação e a vivência das cidades, estão oportunizando que outros campos, como o design, interfiram nestes ambientes. Projetos focados em mobiliário urbano, intervenções e comunicação visual são pensados, em sua maioria, de forma multidisciplinar aliando os conhecimentos técnicos, práticos oriundos de diversas áreas (SILVA, 2014 e LYNCH, 2011).

Lynch (2011) ressalta que as cidades que possuem um planejamento urbano organizado e estruturado, podem aplicar os conhecimentos de design para a reestruturação do ambiente, contribuindo com a construção de imagens fortes e a proposição de soluções para necessidades, além de ressaltar identidades latentes. Outro ponto destacado pelo autor é a aplicação de uma comunicação visual coerente e representativa da cidade. Algumas cidades aplicam estes conceitos; uma delas foi Londres, que utilizou os Jogos Olímpicos de 2012 para reconstruir seu legado, investindo em melhorias de infraestrutura que perduram além do período do evento (MARTINO, 2010, web). A utilização dos eventos esportivos para reconstrução de sua imagem já foi verificada em Barcelona. A cidade utilizou a importância e visibilidade dos Jogos Olímpicos de 1992 para redefinir sua imagem. Utilizando como base o conceito de pertencimento, o design foi utilizado como ferramenta de revitalização (JULIER, 2008). O investimento no design urbano, também pode ser observado no estudo de caso apresentado por O'Dollan (2015, web) em que ele apresenta o investimento intensivo que Londres realizou visando a melhoria de seu transporte público, especificamente em metrô e ônibus, a fim de melhorar o dia-a-dia de seus moradores e turistas, corroborando dessa forma com o tráfego na cidade.

Visualiza-se o design como um facilitador do cotidiano nas cidades em diversos aspectos. Em 2015 a WRI Ross Center for Sustainable Cities lançou um relatório intitulado Cities Safer by Design, que em tradução livre significa: Cidades mais seguras por meio do Design. Este documento relata diversas recomendações para melhorar o dia a dia dos cidadãos nas cidades, apresentando casos reais. Para Welle (apud OBELHEIRO, 2015 web) com "o desenho urbano correto, podemos tornar as cidades mais habitáveis, com ruas mais seguras para todos" Este exemplo, retrata a importância do investimento no design urbano para um espaço mais seguro, agradável e experiencial. Considerando a importância de compreender o contexto da cidade de Joinville, para futura análise de sua imagem no próximo tópico são abordados elementos históricos, sociais e culturais que representam a cidade e auxiliam em sua construção imagética.

\section{Aplicação do método de percepção da imagem da cidade}

Objetivando identificar a imagem da cidade percebida, por meio da experiência por diferentes modais, em Joinville, foi aplicada uma pesquisa de observação direta intensiva, focada na entrevista estruturada (considerada por Lakatos e Marconi [2003] como uma "conversação", um procedimento baseado em entrevistas guiadas por roteiro estruturado, a fim de obter respostas e estabelecer uma relação entre elas). Visando o atendimento do objetivo deste artigo, o roteiro da entrevista foi inicialmente submetido a um pré-teste, sendo o universo de aplicação de três pessoas. Durante a aplicação e análise das respostas, observou-se que este não condizia completamente as necessidades do projeto, dessa forma algumas perguntas foram adaptadas, reformuladas, adicionadas ou excluídas, a fim de atingir os resultados esperados. A segunda ferramenta utilizada para percepção da imagem de Joinville é a observação assistemática, por meio da representação imagética; este tipo de pesquisa considera os sentidos para percepção da realidade; a técnica além de se basear no "ver" e "ouvir" também inclui o exame de fatos ou fenômenos que devem ser estudados (LAKATOS E MARCONI, 2003, 
p.190). O tipo assistemático "consiste em recolher e registrar os fatos da realidade sem que o pesquisador utilize meios técnicos especiais ou precise fazer perguntas diretas" (IBID, p.192).

Considerando a amplitude da pesquisa e suas inúmeras possibilidades de exploração, dividiu-se esta abordagem em fases, visto as inúmeras oportunidades de exploração da temática. Tendo como universo macro da pesquisa os moradores de Joinville, definiu-se como público chave da primeira fase da pesquisa os jovens adultos segmentados pelo modal utilizado (carro, moto, ônibus, bicicleta e caminhada). $\mathrm{Na}$ fase inicial, para possibilitar a análise em profundidade, foram envolvidas oito pessoas, com idades variáveis entre 20 e 40 anos, moradores da cidade de Joinville há no mínimo dez anos. Homens e mulheres que utilizam diferentes tipos de locomoção pela cidade, com diferentes objetivos: dirigir-se ao trabalho, estudo, resolução de questões diárias ou para lazer. Na segunda fase, o instrumento de representação imagética foi aplicado com vinte cinco pessoas, a fim de desdobrar os resultados da pesquisa; neste artigo serão analisados o resultado da primeira fase de coleta de informações.

O roteiro da entrevista foi estruturado com base no método estabelecido por Lynch (2011), para análise de três cidades norte-americanas: Boston, Jersey City e Los Angeles. O estudo foi inicialmente publicado em 1960, sendo baseado na pesquisa e experiência empírica e ancorado na percepção dos cidadãos. Ferreira (2011, apud Lynch 2011, p.VII) afirma que o empirismo visualiza o mundo como "uma infinidade de pequenos fragmentos não necessariamente conectados entre si". Logo para entender o todo, é necessário analisar tais fragmentos, bem como relacioná-los por meio dos sentidos. Assim como Lynch (2011, p. 17) "para entender o papel desempenhado pelas imagens ambientais na vida urbana foi preciso examinar detalhadamente algumas áreas citadinas e conversar com seus habitantes". A região escolhida para análise inicial da imagem de Joinville, foi a região norte da cidade, compreendendo os bairros Bom Retiro, Santo Antônio, Costa e Silva, Zona Industrial Norte, Glória e América. Tais bairros foram escolhidos, por abrigarem uma importante região econômica, cultural, educacional e social da cidade (Fazem parte do arranjo físico da região grandes empresas, indústrias, campus universitário, shopping, comércio local, terminal de ônibus, além de uma extensa área residencial) gerando mobilidade por motivos diversificados. Após a coleta das informações estas foram visualizadas com o objetivo de encontrar padrões de repetição e tendências, para que na sequência pudessem ser analisadas; tal estratégia advém da ferramenta pesquisa visual, proposta por Lupton (2013). Em sua essência, esta é utilizada visando identificar oportunidades de mercado ainda não exploradas pelos concorrentes buscando diferenciação e inovação em produtos e serviços. Compreender como os modais interferem nas experiências que os moradores têm da imagem da cidade, identificando sua fisionomia, personalidade e comportamento, é o objetivo central desta análise. Dessa forma no próximo item serão apresentadas e discutidas as informações coletadas, por meio das entrevistas, representação imagética e observação realizada.

\section{Análise da experiência da cidade por diferentes modais}

A aplicação do método de pesquisa permitiu a aproximação com um grupo de moradores, assim percebeu-se que estes têm conexão com a cidade e que em sua maioria, gostam e pretendem ficar na cidade pelos próximos anos. Segundo os respondentes isso se deve as oportunidades de emprego, as relações pessoais construídas, pelo clima e ritmo da cidade. Ao serem questionados sobre o que primeiro lhe vem à mente ao escutar o nome 'Joinville', os entrevistados foram enfáticos: lar, terra natal, indústrias, trânsito e chuva. 
Objetivando a compreensão das diferentes percepções dos cidadãos, ao trafegar na cidade com diferentes meios de locomoção, foram entrevistadas pessoas que utilizam diferentes modais. Ressaltase que alguns dos entrevistados utilizam mais do que um modal nos seus deslocamentos diários, ampliando a riqueza de informações repassadas. Após a exposição dos tipos de transporte que cada entrevistado utiliza, questionou-se sobre as diferenças percebidas ao trafegar pela cidade de ônibus, carro, moto, bicicleta ou caminhando. Os respondentes destacaram que dependendo do trajeto realizado, economiza-se tempo indo de ônibus, visto as faixas exclusivas para estes veículos aceleram a circulação. Entretanto os usuários deste tipo de transporte, ressaltaram a precariedade do serviço em diferentes aspectos, abrangendo desde a pouca disponibilidade de horários, até as estruturas físicas dos terminais urbanos, pontos de ônibus e dos próprios veículos, que em sua maioria estão sofrendo com a ação do tempo e pouco tem sido feito para manutenção destes espaços. Foi destacado ainda a insegurança, principalmente por mulheres, ao trafegar com esta modalidade de transporte. Elas afirmaram que por vezes, passaram por situações de assédio e constrangimento. Outro fator destacado pelos usuários deste tipo de modal é o elevado valor da passagem. Com relação a utilização do carro, os respondentes afirmaram que se sentem relativamente seguros com relação a violência, entretanto ficam apreensivos com a imprudência. Estes usuários afirmaram ainda que é necessária muita paciência para se locomover na cidade principalmente nos horários chave e que os buracos nas ruas e avenidas da cidade estão cada vez maiores e mais constantes, gerando inclusive prejuízos para o modal em determinadas ocasiões. Os adeptos a bicicleta afirmaram que mais do que um meio de transporte este modal é um estilo de vida. Apesar do título de cidade das bicicletas, Joinville possui pouco investimento para segurança dos ciclistas e poucos quilômetros de ciclovia, os ciclistas relataram ainda a prioridade dos carros, ônibus e motos no tráfego diário, a falta de faixas para atravessar em segurança, entre outros aspectos. Mesmo com estes contratempos os ciclistas são fiéis ao seu modal e afirmam que além de ganhar tempo, aumentam a resistência respiratória, condicionamento físico, além de não gerar poluição. Se para os ciclistas os investimentos com infraestrutura para este modal são poucas, há quem diga que a cidade muito investimento neste tipo de transporte. Em recente visita a cidade a cicloativista Renata Falzoni (CVJ TV, 2018, web) declarou estar impressionada com tamanho estímulo para prática do ir e vir com bicicleta, afirmando que são poucas as cidades que convidam as pessoas a pedalarem e Joinville é uma dessas cidades. Tal afirmação, reforça que apesar de poucos investimentos no setor, se comparado com outras cidades, Joinville ainda está à frente neste setor. Os respondentes que utilizam a caminhada como alternativa de transporte, se mostram satisfeitos com o tempo investido para locomoção pela cidade. Grande parte dos itens negativos destacados pelos ciclistas, foram repetidos por estes, em que se destacam empecilhos para locomoção, tais como a falta de infraestrutura, obstrução de passagem, falta de sinalização... Entretanto, foi destacada a melhora da saúde e a qualidade do tempo investido para se locomover, como pontos positivos.

Visando compreender os esquemas mentais projetados pelos respondentes e a percepção que estes possuem do seu trajeto diário, de suas casas até o trabalho (visto que muitos entrevistados percorrem o mesmo trajeto diariamente) buscou-se identificar a qualidade do tempo investido neste percurso, os sentidos despertados com a utilização dos diferentes modais e os marcos deste trajeto. Para melhor compreensão destes itens, foi solicitado que os entrevistados criassem desenhos detalhados de seus percursos diários. Durante esta fase a entrevistadora ficou atenta às reações dos respondentes e a formulação do esquema ilustrativo. Os resultados foram surpreendentes, visto que de acordo com o modal utilizado e o gênero do entrevistado, diferentes sentidos e percepções são afloradas durante o percurso. 
Verificou-se que ao trafegar por uma mesma rua com diferentes modais as percepções são diferenciadas. Cita-se o exemplo da rua Otto Benack, no bairro Bom Retiro. Três respondentes passam diariamente nesta rua (predominantemente no percurso residência trabalho) e utilizam modais diferentes: um utiliza a caminhada, outro o carro e outro a bicicleta. Os sentidos aflorados são variados; destaca-se o olfato, audição e visão no caso do usuário do pedestre que relatou sentir o cheiro da panificadora industrial e dos restaurantes, que existem nesta rua; este indivíduo também destacou a possibilidade de utilização da rede wi-fi de um dos restaurantes quando passa em frente, visto que este é liberado para clientes; declarou ainda, de forma afetuosa, que cumprimenta com um 'bom dia' uma senhora que diariamente está cuidando do seu jardim, ainda de pijama. Destacou os cães que já não latem tanto, enquanto está passando em frente as casas, pois de acordo com o entrevistado, estes já se acostumaram com a sua passagem. Percebe-se a riqueza de detalhes e de relações despertadas por este indivíduo. Outro entrevistado que passa diariamente nesta rua, de carro recordou-se dos inúmeros buracos existentes na rua, dos veículos estacionados nas laterais dificultando o fluxo contínuo da rua, visto que devido ao bloqueio de espaço, quando dois carros transitam, um deles necessita esperar o outro passar. Foi relatado que diariamente é preciso diminuir a velocidade para que um dos moradores da rua saia com seu carro do portão de casa, destacando, ainda, a dificuldade de converter à direita na Avenida Santos Dumont devido ao fluxo intenso de veículos. O condutor de relatou que é sente os aromas da panificadora e do restaurante, entretanto de forma menos impactante. O ciclista relatou que por não haver ciclovia, e em virtude do movimento acentuado da rua, já passou por diversas situações de risco. Destaca-se ainda que as folhagens de algumas árvores fazem com que o ciclista se abaixe ou desvie, se assim o tráfego permitir. Considerando as diferentes descrições do mesmo trajeto, nota-se que de acordo com o modal mudam as percepções. Em linhas gerais, se o indivíduo é influenciado por uma carga de tensão desde o trajeto até a empresa, este já iniciará suas atividades com emoções negativas, prejudicando seu desempenho; ao contrário, se suas percepções forem seu dia não é afetado por emoções negativas vivenciadas no trânsito.

A representação do trajeto (por meio do desenho) realizado de casa para o trabalho foi seguida da descrição verbal do mesmo caminho como se estivesse sendo realizada para uma pessoa que não conhece a cidade. Percebeu-se que conforme Lynch (2011) descreve, as vias são utilizadas em primeiro plano para descrever os passos que devem ser realizados para chegar até o local. Os pontos nodais também foram utilizados com frequência durante as descrições; tais fatos reforçam a coerência da metodologia do autor. Na sequência questionou-se sobre as emoções e sentimentos despertados durante o trajeto. Conforme abordado anteriormente, o repertório e as lembranças de cada entrevistado exerceram influência nesta abordagem. Um dos pontos destacados foi a mágoa com relação a alteração do entorno ao longo dos anos. Um dos respondentes afirmou que contemplava diariamente as grandes e centenárias árvores que embelezavam as laterais do estacionamento de seu local de trabalho, proporcionando sombra aos veículos, que hoje estão dando lugar a ampliação da estrutura física do prédio da empresa. Outro fato destacado por outra respondente são as recordações despertadas ao sentir o aroma das flores e folhagens exaladas durante o verão. A entrevistada afirmou lembrar de sua infância e das férias na casa dos avós. Verifica-se que a cidade é percebida de diferentes formas, de acordo com o repertório de cada cidadão, corroborando com as abordagens de Lynch (2011)

O tempo médio investido pelos respondentes para transitar de suas casas para o trabalho é de 15 a 35 minutos. Destaca-se que um dos entrevistados que utiliza o carro como meio de transporte, afirmou realizar um percurso mais longo, a fim de desviar de ruas de tráfego intenso e 
com muitos buracos, aumentando consideravelmente o tempo despendido para esta atividade. A insegurança é observada em todos os modais. Os respondentes que utilizam a caminhada como forma de locomoção, afirmaram que ficam receosos ao retornar para suas casas ao anoitecer. Um dos respondentes afirmou já ter sido assaltado, ao sair do trabalho, e que tal fato o motivou a procurar outro modal para realizar o percurso, ou, quando necessário ficar mais tempo em seu ambiente de trabalho. Os usuários do carro e moto, também se dizem inseguros com relação a violência e principalmente a imprudência. Já os ciclistas dizem ficar receosos ao trafegar em ruas sem ciclovia, com iluminação baixa e quando necessitam atravessar as vias.

O questionamento que sugeria aos respondentes descrever a cidade para alguém de fora, revelou aspectos peculiares. A chuva, retornou as respostas, sendo uma das primeiras menções da maioria. Outro item pontuado foi o trabalho, fazendo referência a força da indústria joinvilense. $O$ trânsito, principalmente nos horários chave do dia, foi citado por muitos como um ponto crítico. Em síntese, as descrições revelaram uma cidade com problemas de mobilidade, mas com diversas oportunidades. Joinville possui uma configuração descentralizada, ou seja, seus bairros são independentes, oferecendo autonomia a seus moradores. Este fator foi percebido durante a fase de observação da cidade e constatada durante as entrevistas. Os cidadãos encontram o que precisam, resolvem suas questões diárias, além de trabalhar e residir nos bairros. Questionado sobre a última vez que foi ao centro da cidade, um dos entrevistados afirmou não se recordar, justificando que consegue realizar todas as suas atividades e satisfazer todas as necessidades no bairro em que mora ou próximo dele. Outro respondente, afirmou que este formato facilita o dia a dia, visto que promove rapidez no cumprimento de suas tarefas. Foi destacado, que para resolução de questões legais, ainda há a necessidade de se locomover até a região central, citam-se os cartórios, sindicatos, órgãos públicos, que estão localizados no centro. A descentralização é uma característica reforçada pela falta de estrutura oferecida pelo centro da cidade. A região é antiga, com ruas estreitas, falta de estacionamento e constantes atos de perturbação pública. Os entrevistados destacaram que a Rua das Palmeiras e a Rua do Príncipe, marcos da história da cidade, estão afetadas por vândalos, tráfico de drogas e pedintes. Esta imagem assusta e afasta os cidadãos e turistas da área central de Joinville. Os prédios históricos, estão em estado de decadência ou escondidos pelos letreiros e fachadas das lojas. Durante a fase de observação, foi constatado o descaso do poder público com a história da cidade, visto o abandono destes lugares.

Ao serem questionados sobre as principais vias da cidade, visualizou-se um resultado interessante: as ruas e avenidas citadas encontram-se em sua maioria nos bairros da cidade e contribuem para conexão entre eles; foram citadas as Avenida Santos Dumont, Beira Rio, Marquês de Olinda e Getúlio Vargas, e, as ruas Ottokar Doerffel, Dr. João Colin, Blumenau, Max Colin e São Paulo. Sobre a orientação na cidade, os respondentes afirmaram que tal aspecto é fundamental para segurança, equilíbrio, harmonia e bem-estar. No que tange a sinalização, percebe-se que este é um item que afeta a imagem de Joinville. Considerando os altos números dos setores de turismo de lazer e principalmente de negócios da cidade, este é um aspecto que necessita de atenção. Todos os entrevistados afirmaram já ter passado por situações de ansiedade e nervosismo ao não encontrar lugares e ao não saber aonde se está. As placas orientativas, estão mal posicionadas e até mesmo os moradores da cidade não conseguem trafegar por algumas áreas sem o auxílio de dispositivos móveis de localização, visto a extensa área territorial. Questionados sobre cidades que possuem uma boa orientação, quatro entrevistados citaram Jaraguá do Sul, outras cidades lembradas foram Curitiba, Balneário Camboriú e Belo Horizonte. Os pontos positivos das cidades citadas, são de acordo com os respondentes, as placas da cidade, visto que com base nelas, o 
indivíduo consegue se locomover e chegar a pontos turísticos e de relevância no local. Um dos respondentes afirmou que nos momentos em que há pontos nodais, há indicações para o caminho que deve ser seguido. Percebe-se que a orientação é um ponto crítico de Joinville, que é dificultado ainda mais em dias de chuva. Visto a constante citação desta característica climática, questionouse sobre a estrutura cidade considerando os dias chuvosos. As respostas foram enfáticas e demonstraram que, mesmo sendo está a mais forte característica da cidade, não é oferecida estrutura física e de mobilidade para estes períodos.

A vigésima primeira pergunta permitiu que os respondentes expressaram suas sugestões para melhoria do espaço urbano da cidade. As recomendações variam desde a reconfiguração do trânsito e das ruas do centro da cidade até a proibição do tráfego de veículos e a transformação de estreitas ruas em calçadões para os cidadãos, melhorando o fluxo, a vivência e a experimentação do espaço. Os entrevistados sugeriram que a revitalização das praças públicas, as reconfigurasse como miniparques e que fosse realizado investimento na comunicação e divulgação das atividades culturais na cidade, bem como, em atividades colaborativas e diferenciadas. De acordo com alguns entrevistados, os terminais de ônibus estão mal posicionados, dificultando o tráfego das regiões; uma sugestão seria atribuir a estes espaços maior integração e descentralização, ou ainda que fosse realizado por meio de vias subterrâneas. Além dos terminais, também foram citados: a melhoria no transporte público em si; aumento nas linhas de ônibus; mais integração entre modais; e, mais infraestrutura urbana. $O$ investimento em precauções com as enchentes, também foi referido como desejo de melhoria, visto as constantes inundações, principalmente em regiões próximas aos rios.

Em uma palavra, Joinville foi definida repetidas vezes como trabalho e lar. Em uma imagem, ela foi idealizada como um abraço, que pode ser traduzido como acolhimento. Já considerando a descrição da cidade como uma pessoa (visando intuir sua personalidade) ela foi descrita como uma mulher, muito bonita e atraente, de idade adulta, executiva, workaholic, que aos poucos está descobrindo que é importante relaxar, ter momentos de lazer e experimentação da vida. Uma mulher confiante, mas ao mesmo tempo em busca da construção de sua identidade. Dessa forma, percebe-se que a cidade de Joinville, conhecida por sua força industrial, está permitindo aos poucos, em sua maturidade, uma vivência diferenciada do seu cotidiano. Questionados sobre informações adicionais que desejavam expor sobre a cidade alguns entrevistados afirmaram que Joinville possui múltiplas faces. Segundo um dos entrevistados a cidade é formada por minicidades, e explicou a referência citando como exemplo as regiões norte e sul, que divergem muito em estrutura física, organizativa e visual; destacou que se sente em outra cidade, dependendo da região onde está trafegando.

Percebeu-se um intenso envolvimento dos entrevistados com a pesquisa, ambos expressaram interesse em contribuir para o alcance dos resultados deste estudo. Dessa forma, percebeu-se a preocupação destes com a construção e melhoria contínua da cidade. Os resultados destacam uma cidade multicultural, focada no trabalho, principalmente na atividade industrial, que se desenvolve deixando de lado em alguns momentos a sua história, mas que valoriza traços de sua colonização. Uma cidade com diversos problemas de mobilidade e planejamento urbano, que aos poucos está aderindo a nova cultura de cuidado e experimentação da cidade.

\section{Considerações finais}

A imagem da cidade é percebida no domínio imaterial, por meio de modelos mentais construídos com base nos elementos visuais materiais da cidade e no repertório de cada indivíduo. 
O contexto apresentado, reforça a teoria de Santaella e North (2008), sobre a impossibilidade de separação dos domínios, visto que é por meio de um, que o outro se materializa. O design em paralelo a outras áreas do conhecimento, inseridos no contexto urbano, auxilia na construção de uma identidade sólida, bem como na comunicação visual e segurança da cidade. Percebe-se uma valorização do espaço urbano e uma necessidade de vivência destes espaços, dessa forma a projeção de lugares que valorizam a segurança, a mobilidade e a identidade se fazem necessários.

Objetivando a análise da experiência da cidade por diferentes modais, considerando sua fisionomia, personalidade e comportamento, que os moradores de 20 a 40 anos atribuem a cidade, observou-se que Joinville é uma cidade acolhedora, movida pela força de sua indústria, marcada pela chuva e por diversos signos. Uma forte característica da cidade é a descentralização, ou seja, seus bairros são independentes, oferecendo diversos serviços, moradia e trabalho para os moradores. As múltiplas faces da cidade também foram destacadas pelos respondentes, que afirmaram que ao transitar pelas diferentes regiões da cidade, um novo contexto é apresentado. Os diferentes modais utilizados refletem a percepção que os indivíduos possuem da cidade. Percebeu-se que os sentidos estimulados alteram a significação dos espaços urbanos, interferindo nas atividades cotidianas dos cidadãos.

Com base nos resultados obtidos e aprofundamento teórico apresentado verifica-se a importância do investimento nas mais diversas áreas da cidade, desde a comunicação visual, como na identidade, a fim de culminar em uma imagem positiva para moradores, atraindo consequentemente novos negócios, serviços e perspectivas para cidade. Como possibilidades de novos estudos pertinentes a temática, destaca-se a aplicação desta entrevista com diferentes públicos, desde crianças até a terceira idade, a fim de compreender a percepção da cidade nas variadas segmentações. Outra possibilidade seria a aplicação junto aos moradores de rua, tal esforço revelaria um novo olhar da cidade, que muitas vezes é esquecido. Da mesma forma, abordar a imagem da cidade percebida pelos turistas, revelariam aspectos diferenciados. Outro cenário de abordagem desta temática é o trabalho junto às crianças e adolescentes nas escolas, realizando oficinas e explorando o pertencimento, despertando os jovens a serem os agentes de mudança nas cidades.

\section{Referências}

ALBERNAZ, Patrícia da Cunha. Curta Brasília: a imagem da cidade no olhar do cinema e sua relação com o turismo. 2009. 181 f. Dissertação (Mestrado em Turismo) - Universidade de Brasília, Brasília. 2009.

ANHOLT, Simon. Places: Identity, Image and Reputation. New York: Palgrave Macmillan, 2010. CARDOSO, Eduardo; SCHERER, Fabiano de Vargas e ZAVADIL, Priscila. A imagem da cidade. Jun. 2011. Disponível em: <https://goo.gl/DYF645>. Acesso em: 14 jul. 2015.

CONTRERA, Malena Segura; HATTORI, Osvaldo Takaoki. Publicidade e Cia. São Paulo: Thompson, 2003.

CREUZ, Morgana; EVERLING, MARLI TERESINHA. Intervenções urbanas: o cidadão como agente da cidade. In: Morgenstern, Elenir; Aguiar, Victor. (Org.). Design, cultura e sociedade: limites e reciprocidades. 2ed.Joinville: Univille, 2016, v. 2, p. 152-171.

CVJ TV. Renata Falzoni em Joinville. Disponível em: <https://goo.gl/W2hYf5>. Acesso em: 11 mar. 2018.

DEBRAY, Régis. Vie et mort de l’image: une histoire du regard en Occident. Paris: Gallimard, 1992. 
FERREIRA, Aurélio Buarque de Holanda. Novo dicionário Aurélio da língua portuguesa. 4.ed. Curitiba: Positivo, 2009.

FLUSSER, Vilém. Filosofia da caixa preta. Rio de Janeiro: Conexões, 2002.

GASTAL, Susana. Turismo, imagens e imaginários. São Paulo: Aleph, 2005.

GEHL, Jan. Cidades para pessoas. Tradução de Anita di Marco. São Paulo: Perspectiva, 2013.

JACOBS, Jane. Morte e Vida de Grandes Cidades. Tradução de Carlos S. Mendes Rosa. 3 ed. São Paulo: WMF Martins Fontes, 2011.

JOLY, Martine. Introdução à análise da imagem. 6. ed. Campinas: Papirus, 1996.

JULIER, Guy. La cultura del diseño. Tradução de: Marcos Muslera. Barcelona: GG Disenõ, 2008.

KOTLER, Phillip. Administração de marketing. 10 ed. São Paulo: Printice Hall, 2000.

LAKATOS, Eva Maria; MARCONI, Maria de Andrade. Fundamentos de metodologia científica. 5 ed. São Paulo: Atlas, 2003.

LEFEBVRE, Henri. Direito à cidade. 4. ed. São Paulo: Centauro, 2006.

LUPTON, Ellen (Org.). Intuição, ação, criação graphic design thinking. São Paulo: Gustavo Gili, 2013.

LYNCH, Kevin. A imagem da cidade. São Paulo: Editora WMF Martins Fontes, 2011.

MALHEIROS, Ubiraélcio da Silva. Arte pública como imagem da cidade: seus trânsitos e apropriações. Arteriais: Revista do Programa de Pós-Graduação em Artes - ICA - IPVA, Pará, v.01, n.01, p.73-79, jan.-jul. 2015.

MARTINO, Victor de. Revitalização de área carente em Londres pode ser exemplo para Rio 2016, diz consultor. Disponível em < https://goo.gl/ALyM4s>. Acesso em: 27 jul. 2015

MAZETTI, Henrique Moreira. Intervenção urbana: representação e subjetivação na cidade. In: CONGRESSO BRASILEIRO CIÊNCIAS COMUNICAÇÃO-UNB, 29, 2006, Brasília. Anais... SP: Intercom, 2006. CD-ROM

MORAES. Dijon. Design e complexidade. In: KRUCKEN, Lia; MORAES, Dijon; (orgs). Coleção: Cadernos de Estudos Avançados em Design, Transversalidade. Belo Horizonte: UEMG, 2008.

O'DOLLAN, Catriona. Pedestres ajudando a encontrar seu caminho em Londres (Reino Unido). Disponível em: <https://goo.gl/64t67h >. Acesso em: 27 jul. 2015.

PLAZA, Julio. Imagens e gens de imagens. Folha de S. Paulo, São Paulo, 14 nov. 1986. Folhetim, p. B8-9. ROMÃO, José Eustáquio. Paulo Freire e a imagem. Educação e Linguagem - Universidade Metodista de São Paulo, São Paulo, v. 13, n. 22, p. 77-97, jul. - dez. 2010.

SANTAELLA, Lucia; NÖRTH, Winfried. Imagem: cognição, semiótica e mídia. São Paulo: Iluminuras, 2008.

SENNETT, Richard. Carne e pedra: o corpo e a cidade na civilização ocidental. Tradução de Marcos Aarão Reis. Rio de Janeiro: Editora Record, 2003.

SILVA, Elisangela Batista da. Olhe bem a cidade: design emocional, place branding e a marca de Belo Horizonte. 2014. 122 f. Dissertação (Mestrado em Design) - UEMG, Minas Gerais. 2014.

SILVEIRA, Jane Rita Caetano da. A imagem: interpretação e comunicação. Linguagem em (Dis)curso - LemD - UNISUL, Tubarão/SC, v. 05, n. esp, p. 113-128, 2005. 